\title{
Pharmacological Resistance of Stress Enhanced Fear Learning in an Animal Model of Post-Traumatic Stress Disorder
}

\author{
Virginia Long, Wendy Fujioka, Dorsa Amir and Michael Fanselow \\ University of California, Los Angeles
}

USA

\section{Introduction}

In anxiety disorders such as PTSD, normal fear responding and learning, which is adaptive and helps us survive, is altered in such way that fear becomes maladaptive, interfering with an organism's ability to alter and adapt behavior in situationally appropriate ways. Maladaptive fear learning is thought to underlie the behavioral symptoms of anxiety disorders such as PTSD (Charney, 2004; Rosen \& Schulkin, 1998) when fear and fear responses dominate behavior even in benign circumstances. The fear learning circuit normally participates in adaptive learning and response to danger, however after trauma some individuals show symptoms of PTSD such as: abnormal response to milder stressors, increased vigilance and startle response (American Psychiatric Association., 2000). Stress enhanced fear learning (SEFL) models some specific aspects of PTSD. Using this model we can examine the consequences of trauma--how acute stress or a traumatic event permanently alters the way fear is learned and how these permanent changes in the fear learning circuitry produce maladaptive responses and maladaptive fear learning.

Post-traumatic stress disorder (PTSD) is an anxiety disorder that is debilitating and profoundly affects the lives of men and women worldwide. The Diagnostic and Statistical Manual of Mental Disorders (DSM) criterion for a diagnosis of PTSD requires exposure or experience of a traumatic or life-threatening event (American Psychiatric Association., 2000). Trauma may be caused by combat, violence (such as assault, rape, robbery), severe accidents, disasters (natural or man-made). Any one of these traumatic events will be experienced by one-third of the population (Brunello et al., 2001). While the majority of people will not develop PTSD, it is estimated that 10 to $20 \%$ of people who experience an acute traumatic event will develop the disorder (Brunello et al., 2001). Symptoms of PTSD include re-experiencing of the trauma, avoidance, and hyper-arousal. Re-experiencing of the trauma can manifest as vivid and emotionally intense memories of the event in flashbacks, nightmares, or ruminations that give the patient a feeling of re-living the trauma. Avoidance of situations, people, or places that remind patients of the trauma is another aspect of the disorder. Increased physiological and psychological arousal, including enhanced startle response and hyper-vigilance also contribute and are indicative of the maladaptive fear learning associated with PTSD.

PTSD is thought to be much more prevalent than the estimated 7.8\%. Furthermore, many cases of PTSD may be unreported and thus undiagnosed (Brunello et al., 2001). 
Compounding the difficulty of diagnosis, PTSD is frequently co-morbid with other anxiety disorders, major depression and substance abuse (Goisman et al., 1998; Kessler, Sonnega, Bromet, Hughes, \& Nelson, 1995), making therapeutic treatment a challenge and in some patients ineffective (Brunello et al., 2001).

Some types of therapy used to treat PTSD include cognitive behavioral therapy (CBT), exposure therapy, systematic desensitization, psychotherapy, and pharmacological therapies. Treatments such as CBT, which include exposure therapy, are a primary treatment for anxiety disorders including PTSD and these therapies can be effective treatments for some features of PTSD, for reviews see (Olatunji, Cisler, \& Deacon, 2010; Roberts, Kitchiner, Kenardy, \& Bisson, 2010). However, behavioral (exposure) therapy is not entirely effective in eliminating symptoms such as exaggerated responses to milder reminder stimuli (Craske et al., 2008).

Pharmacological treatments for PTSD are also common. Anti-depressant drugs such as selective serotonin reuptake inhibitors (SSRIs) are among the drugs that are frequently prescribed in the initial treatment of PTSD symptoms (Berger et al., 2009). Often medications that have been developed for use in other psychological disorders (depression, anxiety, antihypertensives, anti-psychotics) are used to treat PTSD (Hamner, Robert, \& Frueh, 2004); however, because the mechanisms of PTSD are not clearly understood pharmacological treatments have also been only partially efficacious. Thus, marginal improvements in PTSD symptoms produced by treatments such as CBT and pharmacotherapy may be because they are not addressing some of the underlying neurobiological changes that lead to some of the maladaptive symptoms of PTSD.

Animal models of PTSD can capture some of the behavioral and neurobiological symptoms of the disorder and are useful as tools to examine specific aspects of maladaptive fear learning that cannot be studied in humans. These models use various methods for simulating a traumatic event; exposure to predator scent, restraint, and Pavlovian fear conditioning that uses tone-foot-shock pairings are among the most common methods. Stress enhanced fear learning (SEFL), however, is an animal model of PTSD that uses unsignaled, unpredictable foot-shock to mimic and induce trauma; using SEFL we examine how new fear learning after trauma is sensitized. The hallmark of SEFL is an exaggerated fear learning to a mildly aversive stimulus (Rau, DeCola, \& Fanselow, 2005); the animal learns to fear contextual cues formed in an environment that is distinct and distinguishable from the environment where the trauma took place, but after receiving a single shock responds with exaggerated fear, as if it were in the trauma environment. Thus, in SEFL as in PTSD, fear learning that is normally an adaptive process that helps the animal survive becomes maladaptive and disruptive to normal functioning when inappropriate fear responses are triggered. Using SEFL we can examine two aspects of learning that occur as a result of traumatic stress: the associative component, which is fear learning that is directly conditioned to the contextual cues present during the trauma, and the non-associative component, which is more like sensitization in that new fear is acquired after trauma that is disproportionate and not directly related to the trauma (Ponomarev, Rau, Eger, Harris, \& Fanselow, 2010). In the following experiments we examine the efficacy of three compounds on SEFL: midazolam, propranolol, and allopregnanolone.

In Experiment 1 we examined the effects of midazolam, a potent anxiolytic and amnestic agent that readily crosses the blood brain barrier and is a positive modulator at $\mathrm{GABA}_{\mathrm{A}}$ receptors. Midazolam is commonly used pre-operatively in hospitals to alleviate patient 
anxiety and induce amnesia for pre-anesthesia procedures (Bauer, Dom, Ramirez, \& O'Flaherty, 2004). Studies of human memory have found that midazolam induced deficits in declarative memory while sparing implicit memory (Stewart, Buffett-Jerrott, Finley, Wright, \& Valois Gomez, 2006; Thomas-Anterion, Koenig, Navez, \& Laurent, 1999). In animals, midazolam administered prior to restraint stress reduced later conditional responding in an environment where the animals had received foot-shock (Rodriguez Manzanares, Isoardi, Carrer, \& Molina, 2005). However, others studies have found that midazolam altered fear memory in animals that had not experienced prior stress but in animals that had been exposed to prior stress midazolam did not attenuate fear memory (Bustos, Giachero, Maldonado, \& Molina, 2010). Thus, in Experiment 1 we investigated how midazolam-induced amnesia for the trauma would impact subsequent fear learning-if memory for the traumatic event is necessary for SEFL to occur.

Experiment 2 examined the effect of systemic administration of propranolol on SEFL. Propranolol is a commonly used heart medication as a treatment for tachycardia and has also been used to treat performance anxiety; it is often referred to as a specific b-adrenergic (Brantigan, Brantigan, \& Joseph, 1982; Gerber, Freed, \& Nies, 1980) antagonist (although it should be noted that propranolol also influences 5-HT receptors by inhibiting re-uptake of serotonin). Propranolol has more recently been examined as a possible treatment for PTSD (Vaiva et al., 2003). Increased responsiveness of the noradrenergic system in patients with PTSD is thought to underlie some symptoms of the disorder (Southwick et al., 1999) as well as enhance memory formation (Cahill, Prins, Weber, \& McGaugh, 1994; Liang, Juler, \& McGaugh, 1986). b-adrenergic blockade is thought to dull emotional responsiveness and decrease physiological hyper-arousal (Southwick et al., 1999). Thus, propranolol, because of its pharmacological action at noradrenergic receptors in both the peripheral and central nervous systems is an attractive treatment for symptoms of PTSD. However, the results from experiments in both humans (Kindt, Soeter, \& Vervliet, 2009; McGhee et al., 2009; Vaiva et al., 2003; van Stegeren, Everaerd, \& Gooren, 2002) and animals (Cahill, Pham, \& Setlow, 2000; Muravieva \& Alberini, 2010) have been inconsistent. In Experiment 2 we wanted first to determine if peri-trauma (administration of the drug both before and after trauma) injections of propranolol would mitigate SEFL, and second to determine if propranolol had an effect upon the memory for the trauma.

In Experiment 3 we examined how acute administration of the neurosteroid allopregnanolone (3-a-hydroxy-5 a -pregnan-20-one) would affect SEFL. Allopregnanolone is a powerful positive allosteric modulator of $\mathrm{GABA}_{\mathrm{A}}$ receptors containing the a4 and $\mathrm{d}$ subunits (Smith, Shen, Gong, \& Zhou, 2007). Thus, allopregnanolone enhances GABAergic transmission, increasing inhibitory influence of the neurons resulting in anxiolysis, sedation, and analgesia (Belelli \& Lambert, 2005). Evidence from functional magnetic resonance imaging (fMRI) studies show that the amygdala, which is known to be important in fear learning, recognition and expression, was observed to be over-active in patients with PTSD (Rauch, Shin, \& Phelps, 2006; Rauch et al., 2000). GABAergic disinhibition can produce increases in neural excitability and plasticity that may lead to pathological anxiety (Rainnie et al., 2004; Shekhar, Truitt, Rainnie, \& Sajdyk, 2005), and levels of allopregnanolone in plasma as well as in the brain are increased in response to acute stress. These increases in allopregnanolone are thought to act as a regulatory mechanism that restores balance between excitatory and inhibitory neurotransmission after stress (Barbaccia, Concas, Serra, \& Biggio, 1998; Purdy, Morrow, Moore, \& Paul, 1991). In patients with PTSD, decreased 
levels of allopregnanolone in cerebrospinal fluid have been observed and severity of symptoms was correlated with low levels of allopregnanolone (Rasmusson et al., 2006). In mice that experienced social isolation stress and enhanced contextual fear conditioning, structures involved in fear learning (hippocampus, amygdala, and frontal cortex) showed decreased levels of in allopregnanolone (Pibiri, Nelson, Guidotti, Costa, \& Pinna, 2008). Systemic injections of either allopregnanolone or S-norfluoxetine mitigated the enhanced contextual conditioning, presumably by exerting their effects at $\mathrm{GABA}_{\mathrm{A}}$ receptors containing the a4, a6 and d subunits where neurosteroids have high affinity (Pibiri et al., 2008; Pinna, 2010). Changes in gene expression in the SEFL phenotype reveal downregulation of several $\mathrm{GABA}_{\mathrm{A}}$ receptor subunits, among the down-regulated receptor subunit types are the a4 subunits (Ponomarev et al., 2010). Therefore, we boosted circulating levels of allopregnanolone during traumatic stress or during the single shock trial in order to examine if allopregnanolone could mitigate trauma induced over-activation in the brain by enhancing GABAergic transmission globally, thus decreasing SEFL.

\section{Method}

\subsection{Subjects}

In the following experiments subjects were experimentally naïve adult male Long-Evans rats purchased from Harlan (Indianapolis, IN). At the beginning of the experiment rats were 90 days old and weighed 340-370g. Rats were housed individually on a 12-hour light/dark cycle with free access to food and water. Animals were initially handled 1-2 minutes per day for a week prior to the start of Experiment 1. Procedures used in these experiments were conducted in accordance with the Division of Laboratory Animal Medicine and approved by the Animal Research Committee at the University of California, Los Angeles. For Experiments 1 and 2, 32 rats were used for each experiment; in Experiment 3, 40 rats were used.

\subsection{Apparatus}

\subsubsection{Experiment 1}

Procedures took place in two distinct training/testing environments, Context A, the trauma environment and Context B, the novel environment. Each context contained distinguishable background noise, lighting, and odor in fear conditioning boxes that differed in interior size/shape, texture and grid floor pattern designed to minimize generalization between the contexts. Context A chambers $(28 \times 21 \times 22 \mathrm{~cm}$; Lafayette Instruments, Lafayette, IN) were aluminum sided with an opaque Plexiglas back and clear Plexiglas front door piece. Grid floors (18 stainless steel rods, $4 \mathrm{~mm}$ diameter, $1.5 \mathrm{~cm}$ apart) were connected to a shock generator and scrambler (Lafayette Instrument Co.; Lafayette, IN). Overhead fluorescent lighting and a ventilation fan provided $70 \mathrm{~dB}$ of background noise. Fear conditioning boxes were cleaned and dried between each session using a $10 \%$ sodium hydroxide solution. Stainless steel pans were placed beneath each grid floor in the chambers, these contained 4-5 sprays of atomized Simple Green as the context odor. Metal scaffolding attached to a cart was used to transport the animals in their home cages to Context $\mathrm{A}$ and back.

The interior of the Context B chambers, initially the same as described above, were modified by inserting white Plexiglas along the rear wall and two white Plexiglas side-walls at $60^{\circ}$ angles that formed an A-frame. As in Context A, the front door piece consisted of a clear Plexiglas panel. The grid floor, connected to a shock generator and scrambler (Lafayette 
Instrument Co.; Lafayette, IN), consisted of 17 stainless steel rods (4 mm diameter) spaced in offset rows $1 \mathrm{~cm}$ vertically and $2.6 \mathrm{~cm}$ horizontally. Lighting consisted of one red 30-watt incandescent bulb. A white noise generator produced background noise (70 dB, A-scale). Fear conditioning chambers were cleaned, using a $1 \%$ acetic acid solution, and dried between each session. Stainless steel pans were placed beneath each grid floor in the chambers; these contained $4-5$ sprays of an atomized $11 \%$ coconut extract mixture as the context odor. Animals were transported to and from their home cages in a covered, black rubberized box subdivided into four areas by black Plexiglas panels.

\subsubsection{Experiments 2 and 3}

Behavioral testing took place in fear conditioning chambers $(30 \times 25 \times 25 \mathrm{~cm}$, Med-Associates Inc., St. Albans, VT), which were equipped with a Med-Associates VideoFreeze system and sound attenuating chambers. The SEFL 15-shock trauma procedure was conducted in a set of four conditioning chambers (Trauma context); the single shock and SEFL memory test were conducted in a separate set of four conditioning chambers (Novel context). The two contexts were housed in separate rooms and were perceptually distinct from one another, differing in interior chamber shape, room and chamber lighting, scent, cleaning solution, background noise, and transport to the conditioning chambers.

The Trauma context interior was rectangular in shape with aluminum side-walls, a Plexiglas rear wall either with blue dots or covered with an opaque white panel, and a clear Plexiglas hinged front door panel. The grid floors that deliver the electric foot-shocks consisted of evenly spaced standard grid rods (4.8 mm thick, Contextual Conditioning System, MedAssociates Inc.). Chambers received light from sources mounted above each chamber; the room that housed the conditioning chambers was a standard overhead fluorescent light. Stainless steel pans were placed beneath each grid floor in the chambers; these contained 4-5 sprays of atomized Simple Green as the context scent. Fans mounted on each conditioning chamber provided background noise $(60 \mathrm{~dB})$. Animals were transported in their home cages using a portable cart affixed with hanging racks and covered by a white sheet. Between groups of animals chambers were cleaned with 70\% isopropyl alcohol.

For the Novel context, where the single shock and SEFL memory test took place, black plastic inserts were used to create a triangular shape $\left(60^{\circ}\right.$ angles that formed an A-frame) within the conditioning chamber. The rear of the chamber was covered with an opaque white panel, and the front, hinged door was clear Plexiglas. The grid floors consisted of vertically and horizontally off set rods $(4.8 \mathrm{~mm}$ thick, Contextual Conditioning System, Med-Associates Inc.). The black plastic inserts obscured the top lighting within the conditioning chambers, and the room lighting consisted of one red 30-watt incandescent bulb. Stainless steel scent pans contained $4-5$ sprays of atomized $1 \%$ acetic acid solution as the context scent. The background fan in these chambers was turned off $(<50 \mathrm{~dB})$. Animals were transported to and from their home cages in a covered, black rubberized box subdivided into four areas by black Plexiglas panels partially filled with rodent bedding; the subdivided box was transported atop a small rolling cart. Between groups the chambers were cleaned with $1 \%$ acetic acid solution. All chambers were cleaned with a $10 \%$ bleach solution at the end of each day of testing.

\subsection{SEFL procedure and extinction}

Animals were placed into fear conditioning chambers where they received $15(1 \mathrm{~mA}, 1 \mathrm{sec})$ foot-shocks; control animals received equivalent context exposure but without foot-shock. 
The foot-shocks were un-signaled, inescapable and occurred at pseudo random intervals temporally spaced from three to eight minutes apart for a period of 90 minutes. Twenty-four hours later, animals were placed into a novel context. As described above odor, lighting, spatial location, enclosure shape, flooring, and background noise were unique to context (set of four conditioning chambers). In the Novel Context, baseline activity levels and fear were assessed for the first three minutes. Following the initial three minutes the animals were given a single $(1 \mathrm{~mA}, 1 \mathrm{sec})$ foot-shock and level of fear was measured for five minutes. Animals were then returned to their home-cages. The test of SEFL occurred 24 hours later when the rats were returned to the context where they received the single shock; the animals were then given an eight-minute test of contextual fear learning. Control animals received the same amount of exposure to the trauma environment but did not receive foot-shocks. On subsequent days, the control animals received the same treatment as the SEFL group, a single shock in the novel environment and a test of fear to that second environment.

In Experiment 1, extinction took place in the 15-shock trauma context. Animals were placed into the conditioning chambers for five 30-minute context extinction sessions spaced 5minutes apart. Exctinction procedures occurred on the day following the 15-shock SEFL procedure and 24 hours before the single shock in the Novel Context.

\subsection{Systemic injections}

Animals were habituated to positioning and handling associated with i.p. injections for 2-3 days prior to the beginning of each experiment.

\subsubsection{Experiment 1}

On the drug injection day midazolam animals were injected using 29-gauge 0.5 cc sterile insulin syringes. Animals received injections of either $2 \mathrm{mg} / \mathrm{kg}$ of midazolam hydrochloride (Hospira, Inc., Lake Forest, IL, USA) at a concentration of $5 \mathrm{mg} / \mathrm{mL}$ or the equivalent amount of sterile saline $(0.9 \%)$. Injections occurred 20 minutes prior to the start of the 15shock SEFL procedure.

\subsubsection{Experiment 2}

Animals were injected with either DL-propranolol (Sigma-Aldrich, St. Louis, Mo., USA), dissolved in phosphate buffered saline (PBS) for a final concentration of $5 \mathrm{mg} / \mathrm{ml}$, or PBS with 26-gauge sterile syringes. Animals were given injections $(5 \mathrm{mg} / \mathrm{kg})$ both 20 minutes prior to the 15-shock SEFL conditioning and within 20 minutes following the SEFL procedure; thus, animals received either a total of $10 \mathrm{mg} / \mathrm{kg}$ of propranolol or equivalent volumes of PBS over two injections. At this dosage, studies have found that locomotor and exploratory activity was unaffected, but did reduced the effects of predator stress on behavioral measures of anxiety such as social interaction, hole board, light/dark box, elevated plus maze, and after re-activation of memory in an inhibitory avoidance procedure (Adamec, Muir, Grimes, \& Pearcey, 2007; Przybyslawski, Roullet, \& Sara, 1999).

\subsubsection{Experiment 3}

Animals were given i.p. injections (26-gauge sterile syringes) of either allopregnanolone (ALLO, Sigma-Aldrich, St. Louis,

Mo., USA) suspended in a $22 \%$ solution of (2-hydroxypropyl)-b-cyclodextrin solution (CDX) in sterile saline $(0.9 \%)$ for a final concentration of $3 \mathrm{mg} / \mathrm{ml}$, a $22 \%$ solution of CDX in sterile 
saline $(0.9 \%)$, or injections of sterile saline $(0.9 \%)$. Animals were given injections 20 minutes prior to the 15-shock SEFL conditioning; $5 \mathrm{mg} / \mathrm{kg}$ of ALLO and equivalent volumes of CDX solution or Saline. Using this dose of ALLO studies found behavioral effects on alcohol consumption after injections but no adverse side effects in rats (Janak \& Gill, 2003; Janak, Redfern, \& Samson, 1998) and in mice doses of $5-10 \mathrm{mg} / \mathrm{kg}$ or greater are used (Pibiri et al., 2008).

\subsection{Designs and analysis}

\subsubsection{Experiment 1: Midazolam}

Animals were randomly assigned to one of three groups: midazolam pre-trauma (MDZ/Trauma), $n=12$; saline pre-trauma (SAL/Trauma), $n=12$; or saline no-trauma (SAL/No Trauma), $\mathrm{n}=12$. On day 1 all animals received systemic (i.p.) injections of either midazolam or saline followed 20 minutes later by the 15-shock SEFL procedure. Twentyfour hours later, on day 2 all animals were extinguished in the trauma context (Context A) using a massed extinction procedure. On day 3 animals received the single shock in the Novel context and were tested for new fear memory in that context 24 hours later (day 4). Fear memory for the 15-shock trauma context was measured on day 5. For the trauma context fear memory test 2 animals per group were not used due to an experimenter error yielding the following group sizes: midazolam pre-trauma (MDZ/Trauma), $n=10$; saline pre-trauma (SAL/Trauma), $\mathrm{n}=10$; or saline no-trauma (SAL/No Trauma), $n=10$.

\section{Data Analysis}

Freezing scores were used as a measure of learned fear (Fanselow, 1980), and were determined by averaging over behavioral observations (recorded on video tape) made every $8 \mathrm{~s}$ during each test (percentages were calculated by dividing number of observations of freezing by the total number of observations multiplied by 100). Freezing is defined as the lack of movement except for respiration (Fanselow, 1980). Freezing scores were calculated for baseline freezing in Context B prior to the single shock, post-shock freezing in context B, freezing conditioned by the single shock in Context $B$, and freezing in the original trauma context (A). Conditioning and testing were videotaped and a trained, blind observer scored and calculated freezing scores.

Freezing scores were calculated as described above and group differences were analyzed using a one-way analysis of variance (ANOVA) for each designated time period. Statistical significance was determined at $p<0.05$. Post-hoc multiple comparisons among groups were made using Tukey HSD tests in order to specify group differences within each measurement period.

\subsubsection{Experiment 2: Propranolol}

Animals were randomly assigned to one of four groups in a $2 \times 2$ factorial design. Animals were designated by prior experience as having either received either No Prior Trauma or Trauma, and by drug treatment either injected with propranolol or vehicle. Thus the four groups consisted of: No Prior Trauma/Vehicle, $n=8$; No Prior Trauma/Propranolol, $n=8$; Trauma/Vehicle, $\mathrm{n}=8$; Trauma/Propranolol, $\mathrm{n}=8$. On day 1 of the experiment all animals were injected systemically (i.p.) with either propranolol or Vehicle 20 minutes before the start of the 15-shock SEFL procedure. Following the SEFL procedure animals were reinjected with propranolol or vehicle. Twenty-four hours later, on day 2 , all animals were placed in the Novel context where they received a single foot-shock. On day 3 animals were 
tested for SEFL during a fear memory test in the Novel context. Animals were placed again in the trauma context, where they had received the 15 shocks and were tested for fear memory on day 4 .

\section{Data Analysis}

Freezing scores were used as a measure of learned fear (Fanselow, 1980; Fanselow \& Kim, 1994). Freezing behavior was scored using VideoFreeze software (Med-Associates Inc.). During behavioral testing, digital video information from cameras mounted in conditioning chambers was recorded in near-infrared light (NIR). An analysis algorithm that compared pixels of a sample reference frame against real-time continuous frame samples was summed to produce the Motion Index. Activity below a Motion Index of 50 units for duration of 30 frames (or more) per second was scored as freezing. In a validation study, freezing scores generated by the VideoFreeze software and freezing scores generated by human scoring were highly correlated, $\mathrm{r}=0.971, \mathrm{p}<0.0001$ (Anagnostaras et al., 2010); a high correlation between the VideoFreeze scoring and two highly trained observers $(r>0.9)$ has also been reported by this laboratory (Jacobs, Cushman, \& Fanselow, 2010). Average freezing scores were calculated for baseline freezing in the novel context for 3 minutes prior to the single shock; post-shock freezing in the novel context was assessed for 5 minutes. The SEFL test in the novel context and the trauma context fear memory test measured freezing for 8 minutes. Freezing scores were calculated as described above and group differences were analyzed using a two-way analysis of variance (ANOVA) for each designated time period. Statistical significance was determined at $\mathrm{p}<0.05$.

\subsubsection{Experiment 3: Allopregnanolone}

Animals were randomly assigned to one of five groups. All animals experienced the same behavioral procedures: 15-shock trauma, a single shock in the Novel Context, the SEFL test in the Novel Context, and a fear memory test in the Trauma Context. Animals received either ALLO, saline, or CDX vehicle prior to the 15-shock trauma, or ALLO or saline prior to the single shock in the Novel Context. The five groups were as follows: ALLO Pre-trauma, $n=10$; SAL Pre-trauma, $n=10$; CDX Pre-trauma, $n=8$; ALLO Pre-1shk, $n=6$; SAL Pre$1 \mathrm{shk}, \mathrm{n}=6$.

\section{Data Analysis}

Data analysis was similar to data analysis described for Experiment 2, however for Experiment 3 a one-way ANOVA was used to determine statistical significance among groups.

\section{Results}

\subsection{Experiment 1: Midazolam alters fear memory for trauma but does not alter SEFL}

\section{Novel Context baseline fear}

As Figure 1 illustrates all three groups showed very low levels of fear to the Novel context during the 3 minute period before the onset of the single shock. There were no statistically significant differences among the groups, $F(2,33)=1.38, p=0.27$. Lack of group differences in baseline fear indicates whatever fear was acquired during the trauma experience did not generalize to the Novel context. 


\section{Novel Context post-single shock fear}

Fear in the Novel context during the 5 minute period following the single shock was low in the SAL/No Trauma animals while post-shock freezing for both the SAL/Trauma and MDZ/Trauma groups was high. Figure 1 illustrates these group differences. A one-way ANOVA confirmed these group differences, $\mathrm{F}(2,33)=11.98, \mathrm{p}<0.001$, and post-hoc comparisons revealed significant differences between the SAL/No Trauma group $(\mathrm{M}=$ $14.17, \mathrm{SD}=14.67$ ) and both prior trauma groups, however there was no reliable difference between SAL/Trauma animals $(\mathrm{M}=63.54, \mathrm{SD}=35.82)$ and $\mathrm{MDZ} /$ Trauma animals $(\mathrm{M}=$ 43.26, SD = 32.99).

\section{Novel Context: SEFL memory test}

Fear memory for the Novel Context was measured to assess the amount of context specific fear was acquired by the single shock on the previous day. The measure of freezing during the $8 \mathrm{~min} 32 \mathrm{~s}$ test serves as the primary indicator of stress enhanced fear learning. Figure 2 demonstrates this effect; animals that received no prior trauma show a small amount of new fear to the single shock context while animals that received the prior 15-shock trauma display a disproportionately high amount of new fear, that is enhanced fear learning, was unmitigated by experiencing trauma under the drug midazolam. These observations were bourn out by a one-way ANOVA, $F(2,33)=6.33$, $\mathrm{p}<0.01$. Post-hoc analyses confirmed that the SAL/No trauma group $(\mathrm{M}=9.25, \mathrm{SD}=11.26)$ differed from both the SAL/Trauma $(\mathrm{M}=$ $38.93, \mathrm{SD}=24.72)$ and the $\mathrm{MDZ} /$ Trauma groups $(\mathrm{M}=36.33, \mathrm{SD}=28.28)$. There was no reliable difference in freezing between the SAL/Trauma and MDZ/Trauma groups.

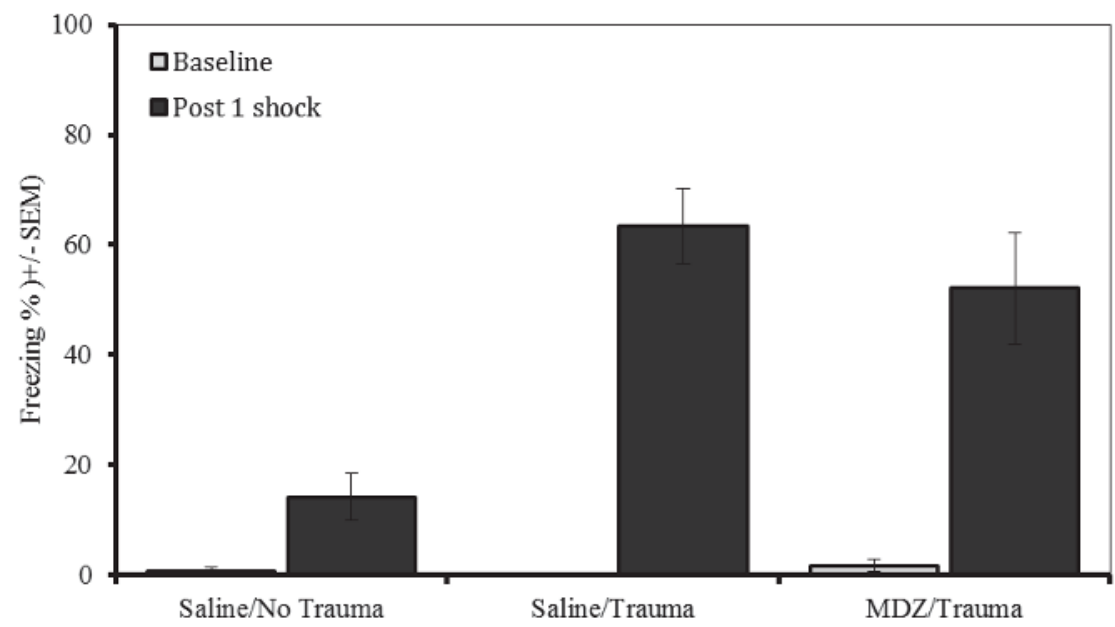

Fig. 1. Experiment 1 Systemic midazolam: Novel Context baseline and post-single shock fear. Mean percent time freezing (+/-SEM) in the Novel context before and after the single shock. All groups showed very low freezing during the baseline measurement period preceding the single shock. Following the single shock animals that did not have prior trauma showed little fear after the single shock, whereas both the saline and midazolam groups that had prior trauma showed high levels of fear following the single shock. 


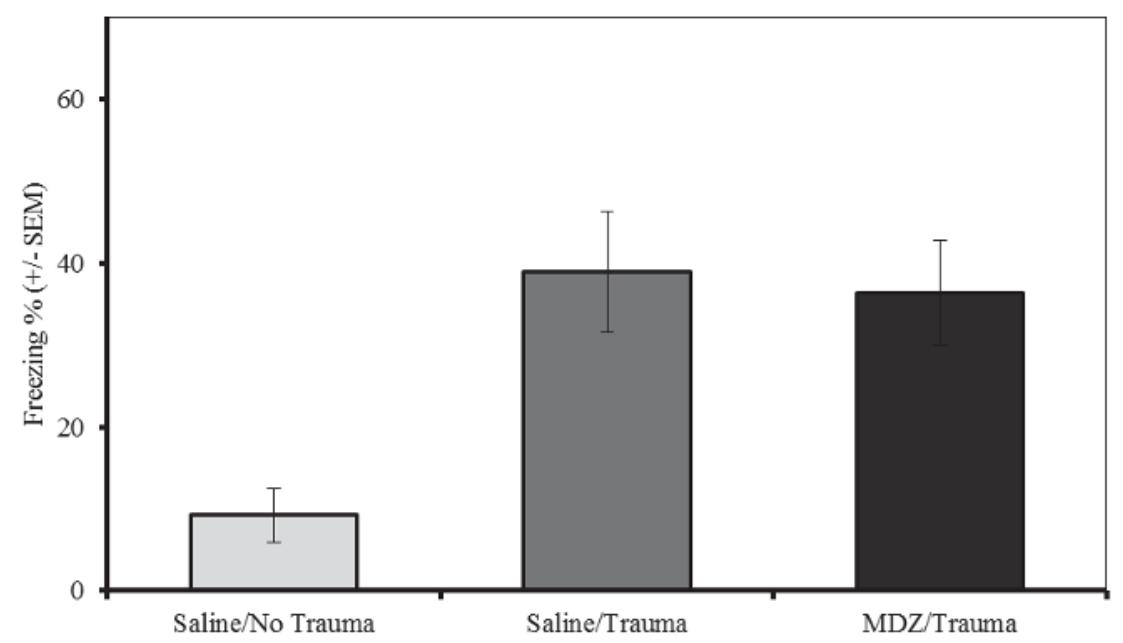

Fig. 2. Experiment 1 Systemic midazolam: Novel Context SEFL memory test.

Mean percent time freezing $(+/-$ SEM) in the novel context 24-hours after the single shock. The saline injected group without prior trauma showed low to moderate levels of fear in the Novel context. The saline and midazolam injected groups that had prior trauma showed equivalent levels of enhanced fear, indicating that midazolam did not attenuate SEFL.

\section{Trauma Context memory test}

Fear memory for the Trauma context was assessed during an $8 \mathrm{~min} 32 \mathrm{~s}$ period on the day following the SEFL test in the Novel Context. As shown in Figure 3 animals that did not receive the prior trauma in this context showed low levels of freezing; animals that received saline injections before the 15-shock trauma displayed comparatively high levels of freezing, while animals that received midazolam before the 15-shock trauma showed a decrease in fear to the trauma context. A one-way ANOVA revealed reliable differences among the groups, $\mathrm{F}(2,27)=3.70 \mathrm{p}<0.05$. Post-hoc analyses confirmed differences between the SAL/No Trauma group $(\mathrm{M}=8.13, \mathrm{SD}=8.52)$ and the SAL/Trauma group $(\mathrm{M}=32.03, \mathrm{SD}=$ $19.66)$, but no reliable difference from the $M D Z /$ Trauma group $(M=25.31, S D=27.81)$. The lack of reliable difference between the MDZ/Trauma group and the SAL/No Trauma group suggests that midazolam altered memory for the traumatic experience; however, the MDZ/Trauma group was also not reliably different from the SAL/Trauma group, suggesting partial amnesia for the trauma.

The findings from Experiment 1 suggest that SEFL is unchanged by manipulations that alter the fear memory for the trauma; neither partial amnesia produced by midazolam in conjunction with massed extinction, nor massed extinction alone were able to diminish SEFL. This is consistent with the findings of Rau et al. (2005) in which neither spaced extinction nor disruption of context fear learning were able to abolish SEFL; spaced extinction over five days, and intra-ventricular administration of the N-methyl-D-aspartate (NMDA) receptor antagonist DL-2-amino-5-phosphonovalerate (APV) effectively eliminated fear in the trauma context, yet SEFL still occurred. Thus, even while the associative 


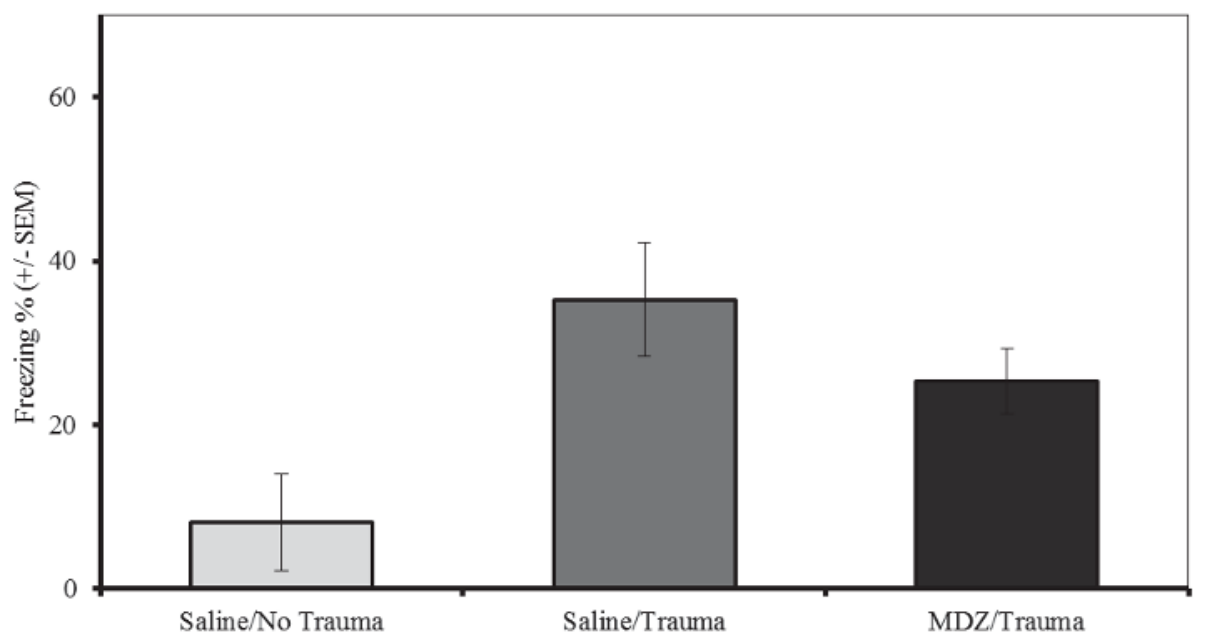

Fig. 3. Experiment 1 Systemic midazolam: Trauma Context memory test.

Mean percent time freezing (+/-SEM) in the Trauma context. Saline injected animals that did not have prior trauma displayed little fear for the trauma context while saline injected animals that did receive the 15-shock trauma displayed fear even after extinction of fear in this context. Midazolam injected animals showed some fear memory for the trauma context, however, compared to saline/trauma counterparts fear memory was diminished.

component of SEFL, the fear directly related to the trauma, can be altered and diminished by various methods, the non-associative sensitization of fear learning remains unaffected. Because both extinction and manipulations of memory for the trauma are exerting their effects upon the associative aspects of trauma-related fear, in Experiment 2 we used propranolol, which has been found to reduce memory enhancements for emotionally arousing material (Cahill, Babinsky, Markowitsch, \& McGaugh, 1995) and has been studied as a possible treatment of PTSD (Vaiva et al., 2003).

\subsection{Experiment 2: Propranolol does not diminish SEFL or alter trauma fear memory}

Novel Context SEFL memory test

As illustrated in Figure 4 animals that received no prior trauma under vehicle or propranolol showed low levels of fear when tested in the Novel environment where they had previously received the single shock, whereas animals that had experienced the 15shock trauma either with vehicle or propranolol showed high levels of fear. These group differences were confirmed statistically; a two-way ANOVA revealed a main effect of prior experience (No prior trauma or Trauma), $F(1,28)=40.51, p<0.001$. There was no main effect of drug and no interaction. These results indicate that propranolol had no effect on the acquisition of new fear in the single shock environment-SEFL was evident in animals that had received prior trauma whether they had received vehicle or propranolol. 


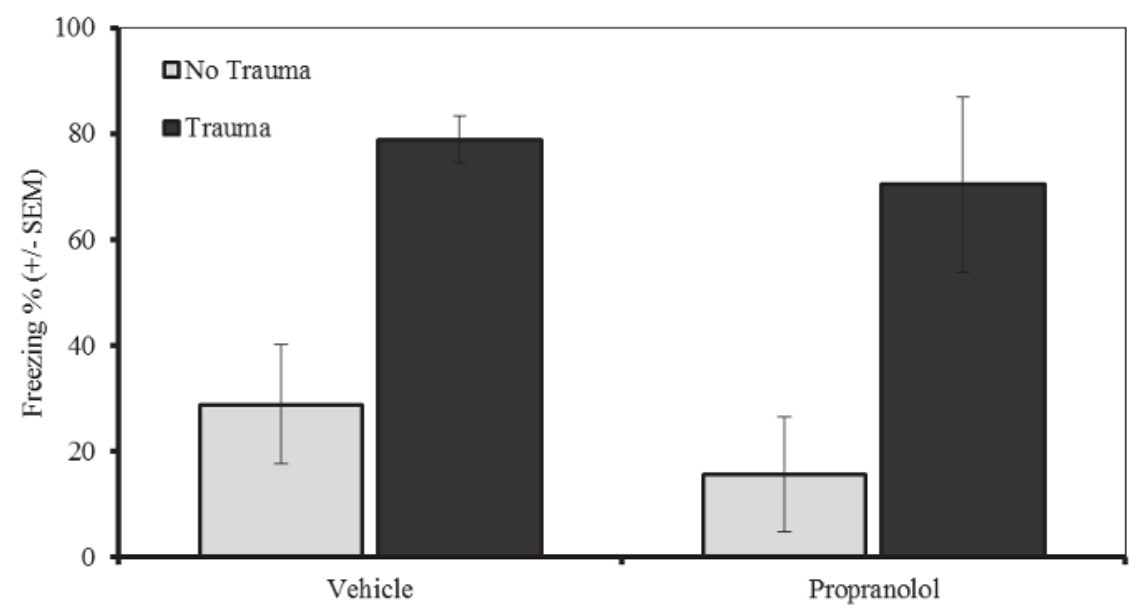

Fig. 4. Experiment 2 Systemic propranolol: Novel Context SEFL memory test.

Mean percent time freezing (+/- SEM) in the Novel context 24 hours after the single shock. Animals that had no trauma and received either vehicle or propranolol did not differ in fear learning to the single shock context. Vehicle treated animals that had prior trauma showed the typical SEFL phenomenon. Propranolol treated animals with prior trauma also showed SEFL, indicating that propranolol administration did not alter subsequent fear learning.

\section{Trauma Context fear memory test}

Animals displayed the same pattern of results as in the SEFL test; regardless of whether animals were treated with vehicle or propranolol, animals that had not received prior trauma showed low levels of fear when returned to the trauma context and animals that had experienced trauma there showed very high levels of fear. This is depicted in Figure 5. Statistical analysis confirmed that there was again a main effect of prior experience (No prior Trauma or Trauma), $\mathrm{F}(1,28)=72.40, \mathrm{p}<0.001$, but no main effect of drug and no interaction. The clear absence of an effect of propranolol suggests that the drug was not producing behavioral changes that should be evident if the drug had altered how the trauma had been experienced.

We found that propranolol, when administered systemically before and after traumatic stress, had no effect on SEFL, nor did it alter fear memory of the traumatic event. Thus, neither the associative nor the non-associative aspects of SEFL were changed by propranolol. The null results of propranolol that we observed may indeed be similar to the findings of McGhee et al. (2009) who found no effect of propranolol on the development of symptoms of PTSD in soldiers who suffered combat related burns. However, these findings are in contrast to Viava et al. (2003) who found that instances of PTSD were reduced when propranolol was given post-trauma to car accident or assault victims. Acute stress is known to engage stress response centrally as well as peripherally. One biological effect of stress in the brain, and a consequence of corticosterone (in rats) release, is endogenous release of the neurosteroid allopregnanolone. Allopregnanolone is co-released from GABAergic neurons and is a positive modulator at $\mathrm{GABA}_{\mathrm{A}}$ receptors, enhancing GABAergic transmission in the brain. Allopregnanolone is produced and released centrally as well as peripherally, crossing 
the blood-brain barrier readily. Thus, in Experiment 3 we examined the effect of boosting levels of available allopregnanolone via acute systemic injections either before the traumatic stress or before the single shock episode.

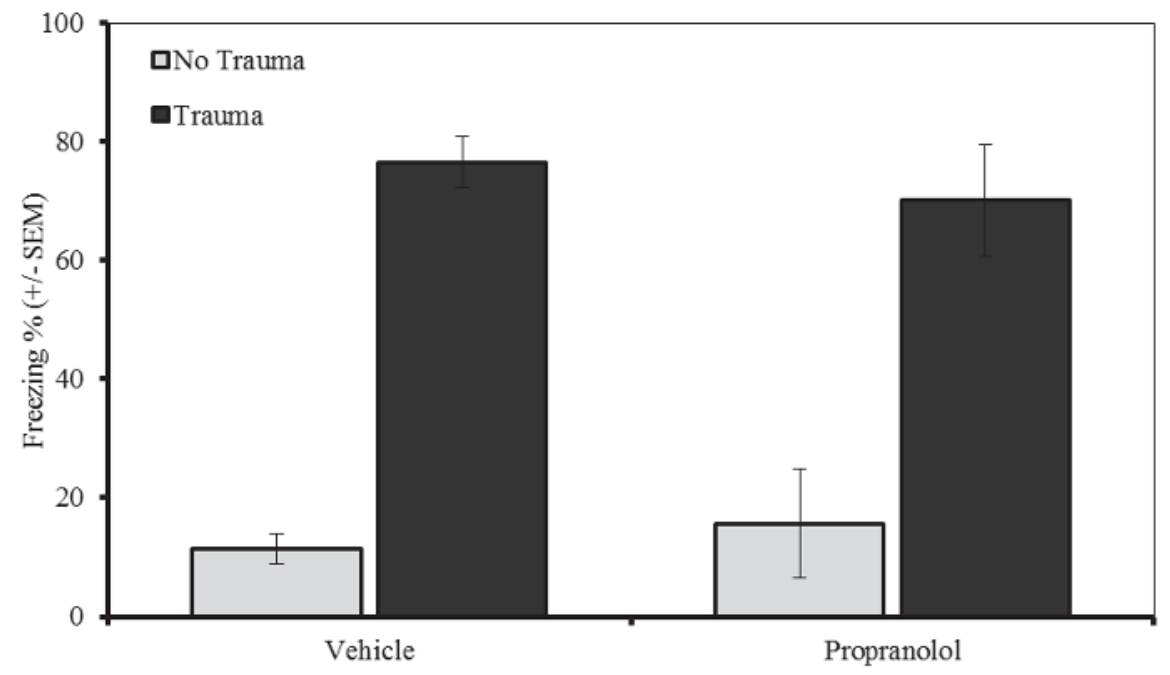

Fig. 5. Experiment 2 Systemic propranolol: Trauma Context fear memory test.

Mean percent time freezing (+/- SEM) in the 15 shock Trauma context. Both vehicle and propranolol injected animals that did not have prior trauma displayed low levels of freezing. Similarly, vehicle and propranolol injected animals that had prior trauma showed high levels of freezing, suggesting that fear memory for the trauma context was not altered by propranolol.

\subsection{Experiment 3: Systemic administration of allopregnanolone does not alter SEFL}

Novel Context SEFL memory test

As illustrated in Figure 6 animals that received ALLO administration prior to the trauma or prior to the single shock showed no reduction in SEFL, and animals in both the saline injection and CDX control groups displayed characteristically high levels of fear in the Novel Context. A one-way ANOVA confirmed that there were no overall group differences, $\mathrm{F}(4,35)=1.60, \mathrm{p}=0.196$. These results suggest that the anxiolytic properties of allopregnanolone were not sufficient at this dose or by this route of administration to mitigate the fear sensitizing effects of prior trauma.

\section{Trauma Context fear memory test}

Figure 7 shows the same pattern of results as seen in the SEFL memory test. ALLO did not attenuate associative fear learning in the Trauma Context. As expected, SAL and CDX controls showed very high levels of fear when returned to the Trauma Context. Group differences were not statistically significant, $F(4,35)=1.51, \mathrm{p}=0.22$. Fear memory for the Trauma environment was not decreased by prior administration of allopregnanolone, suggesting the effect of systemic allopregnanolone had no detectable effects on the 15-shock trauma. 


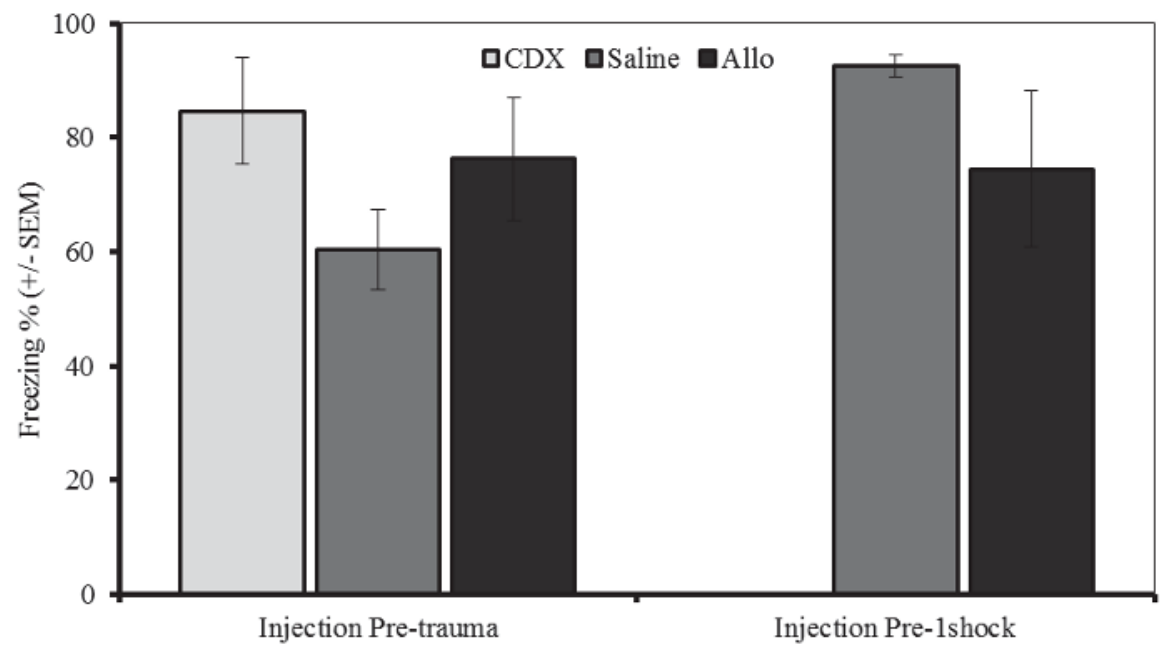

Fig. 6. Experiment 3 Systemic allopregnanolone: Novel Context SEFL memory test.

Mean percent time freezing (+/- SEM) in the Novel context 24 hours after the single shock. Pre-trauma injections of allopregnanolone, CDX, or saline did not reliably diminish exaggerated freezing in the Novel context. In animals that received injections of either saline or allopregnanolone before the single shock there were also no reliable differences.

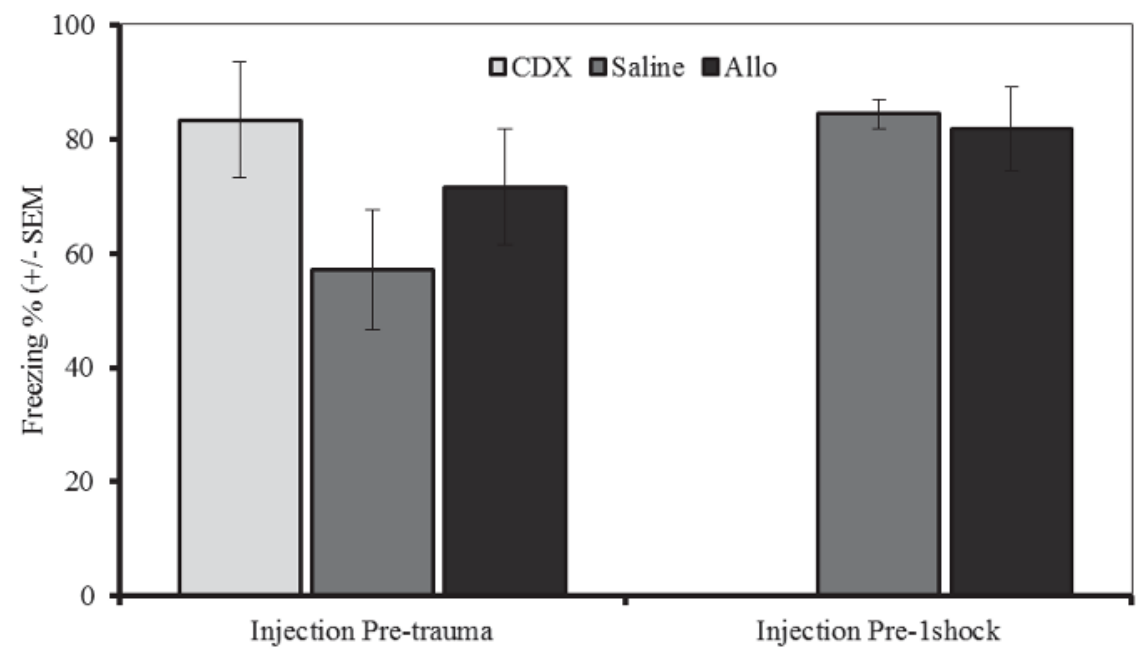

Fig. 7. Experiment 3 Systemic allopregnanolone: Trauma Context fear memory test. Mean percent time freezing (+/-SEM) in the 15 shock Trauma context. Trauma context fear memory was not reliably altered by pre-trauma injections of allopregnanolone, CDX, or saline. Fear memory for the trauma context was not changed by subsequent administration of either saline or allopregnanolone. 
Our results from Experiment 3 indicate that allopregnanolone given in an acute systemic does not attenuate SEFL at the dose of $5 \mathrm{mg} / \mathrm{kg}$. We found that systemic injections of the drug administered either before the traumatic event or before the single shock stressor had no effect on how new fear was acquired subsequent to trauma. These findings are in contrast with those of Pibiri et al. (1998) and Pinna (2010) who found that systemic administration of allopregnanolone reduced negative consequences, such as enhanced contextual fear conditioning, in rats that had experienced social isolation stress.

\section{Discussion}

Our results indicate that SEFL is resistant to pharmacological manipulations that targeted either the GABAergic or noradrenergic neurotransmitter systems. Midazolam, though it appeared to alter the memory for the traumatic event, was ineffective at eliminating SEFL. Indeed, neither midazolam nor allopregnanolone, both of which increase GABAergic inhibition (achieved via potentiation of somewhat different $\mathrm{GABA}_{\mathrm{A}}$ receptor populations) affected SEFL. Nor was SEFL affected by manipulation of noradrenergic transmission using the b-noradrenergic blocker propranolol.

SEFL is a robust behavioral phenomenon that seems to be refractory to several of the pharmacological treatments used to treat anxiety and PTSD; indeed, the SEFL inducing trauma seems to produce behavioral symptoms akin to treatment refractory PTSD where the symptoms of the disorder are not mitigated by behavioral and pharmacological treatments. Additionally, systemic administration of drugs, while useful for clinical translation, is a limited tool in that we cannot specify where in the brain the drug will exert an effect. Indeed, global effects may reflect contradictory actions of the drug; among brain regions it is possible that the lack of drug effects may occur by offsetting actions on different brain regions. While the three compounds that we examined in these experiments all readily cross the blood brain barrier, we should not overlook possible effects of the drugs in the periphery or overlook the role of feedback from the periphery influencing processes in the central nervous system. In these experiments we used acute administrations of each drug on a single day of the experiment. Although the time points for drug administration were chosen in order to assess specific effects upon either the trauma memory or upon single shock memory it is possible that multiple doses following the trauma (more similar to pharmaco-treatment regimes) might have produced a detectable effect.

\section{Limitations of midazolam}

Although midazolam, administered systemically, was likely acting upon diverse regions in the brain, it is believed that the effect of the drug is mainly exerted in the hippocampus (Frank, O'Reilly, \& Curran, 2006). The effect of midazolam on inhibition of neurons within the hippocampus explains midazolam's amnestic quality, GABAergic transmission there would be increased, potentially deterring the formation of declarative memory. Rau et al. (2005) has previously shown that amnesia for the trauma could be induced using intraventricular infusions of APV to block NMDA receptors primarily in the dorsal hippocampus. Thus, memory for the trauma is not necessary to produce SEFL; the associative learning about the trauma can be blocked while the non-associative processes that lead to SEFL are left unchanged. The findings reported here are similar to those reported by Rau, Fanselow, and Eger in (Sher \& Vilens, 2010); when the SEFL test occurred after a five day period between the trauma/drug administration midazolam did not 
diminish SEFL but did alter memory for the trauma. Rau et al. used a 4 foot-shock procedure, which has previously been shown to produce SEFL almost as robustly as the 15 foot-shock procedure (Rau, Oh, Laster, Eger, \& Fanselow, 2009), and although in the current experiments we used the more severe 15 foot-shock procedure, midazolam was still able to diminish the associative memory of the trauma. The dose used in the present experiments was slightly higher than in the Rau et al. experiments $(2 \mathrm{mg} / \mathrm{kg}$ vs. $1.5 \mathrm{mg} / \mathrm{kg})$, however the 15 shock procedure lasts 90 minutes while the 4 shock procedure lasts only 20 minutes. It is possible that midazolam induced only partial amnesia for the trauma context (rather than the abolition of fear observed in the Rau et al., experiments) because of the length of the conditioning sessions; during the latter portion of the 15 shock procedure the midazolam could have been less effective, allowing contextual fear learning in the trauma context to occur.

\section{Limitations of propranolol}

It is possible that time of treatment may be a factor that determines the efficacy of propranolol. Early studies using propranolol were especially exciting because it could be administered after the occurrence of trauma. This is important given the unexpected nature of trauma, and rather than requiring prophylactic administration in case trauma occurs, propranolol could be given to victims of trauma following the event. However, because we administered the drug both prior to and following the trauma we were able to take advantage of propranolol's effect on general arousal (decreasing heart rate and blood pressure (Gerber et al., 1980)) as well as its reported post-trauma effects on emotional memory.

The second difference among studies is the type of trauma: in the human literature, when propranolol was tested for efficacy after combat-related trauma, propranolol was ineffective (McGhee et al., 2009) while propranolol administered after car accidents or assault was found to be effective. We speculate that the 15-shock trauma may have been more similar to the intensity of trauma produced by a combat situation, and that the severity of the trauma is possibly a factor in propranolol's efficacy. Propranolol may be effective in mitigating certain types of trauma while for other types the effect of propranolol may not be powerful enough to ameliorate the effects of severe trauma. There is some evidence that propranolol may be an effective in altering fear memory during re-consolidation (Kindt et al., 2009). However, human laboratory fear learning procedures are far less severe than either exposure to real trauma in humans or foot-shock trauma in rodents. The possibility remains that reconsolidation of learned fear might be altered by the physiological effects of the drug; memories of the trauma that are recalled under propranolol might produce less physiological arousal, decreasing emotional salience. However, SEFL is unchanged by extinction as well as amnesia for the trauma (Rau et al., 2005) and along with our findings in Experiment 1 this suggests that manipulations focused on altering the associative component of SEFL may not be effective.

A third possible difference among the outcomes of propranolol studies is the type of learning or memory that is being evaluated, and what symptoms or behaviors are being measured. Emotional memory per se can be studied in rodents, by measuring freezing to assess fear learning and expression; however in human studies self-report measures or galvanic skin response are often employed. Additionally, studies of emotional learning and memory often focus on associative symptoms directly related to the traumatic event; however, SEFL is a phenomenon that illustrates a non-associative processes and behavior 
that is indicative of a sensitization of fear learning-most studies do not look at these processes. These non-associative processes, however, are likely to be significant contributors to PTSD symptomology.

Emotionally arousing stimuli may increase noradrenergic activity and thereby enhance memory (Cahill et al., 1994; Roozendaal, Okuda, de Quervain, \& McGaugh, 2006), but this effect may be limited to milder emotionally arousing situations. It is possible that in our findings we did not detect any diminution of enhanced memory in the propranolol group because of the strong emotional effect produced by the 15-shock trauma. Perhaps if the trauma procedure was less emotionally arousing it might be possible to discern an effect of propranolol. Reist et al. (2001) found that propranolol had the same effect of reducing recall for an emotionally arousing story in patients with PTSD as for control subjects, suggesting that propranolol might be effective at reducing memory for subsequent milder stressors that lead to behavioral phenomena like SEFL. However, this suggests that propranolol would not be an effective treatment for the most severe aspects of PTSD, which are those most in need of treatment.

Paradoxically, extreme arousal of the NE system causes memory deficits (Kobori, Hu, \& Dash, 2010). In this regard it is possible that propranolol was actually having a dulling effect on the trauma memory so that the lowered NE arousal allowed memory formation about the trauma when it might otherwise have been decreased. However, given the data from the control groups, which show identical levels of trauma context fear, the animals without propranolol were able to learn and remember the trauma context as well as their propranolol counterparts.

Limitations of allopregnanolone

Allopregnanolone has been shown to produce behavioral changes in other paradigms such as in operant conditioning experiments looking at voluntary alcohol consumption. Behavioral effects at doses of allopregnanolone that were similar or even lower than the dose used in Experiment 3 have been observed (Janak \& Gill, 2003; Janak et al., 1998); doses of $3 \mathrm{mg} / \mathrm{kg}$ and $5.6 \mathrm{mg} / \mathrm{kg}$ increased alcohol consumption, suggesting that the reinforcing properties of alcohol, exerting its effects at the $\mathrm{GABA}_{\mathrm{A}}$ receptors containing a4 subunits, was enhanced with the administration of allopregnanolone.

There is evidence that tonic GABAergic inhibition via interneurons in the basolateral amygdala are responsible for modulation of excitatory projection neurons in this region (Ehrlich et al., 2009), and that GABAergic disinhibition produces increases in neural excitability and plasticity leading to pathological anxiety (Rainnie et al., 2004; Shekhar et al., 2005). We had hypothesized that by elevating circulating levels of allopregnanolone before trauma that the neurosteroid might be able to enhance GABAergic response to the traumatic stress, thereby impeding over-activation of brain regions involved in fear learning and the consequent long-term effects of trauma. A single acute administration of allopregnanolone, however, may not have a strong enough influence on the fear circuitry to counteract the effects of trauma. SEFL is a long-lasting behavioral effect that has been observed as long as 90 days after the initial trauma (Rau 2009). Thus, the trauma seems to be permanently altering the fear learning circuit and it is likely that a transient boost in allopregnanolone was not able to mitigate the effects of trauma.

Down-regulation the $\mathrm{GABA}_{\mathrm{A}}$ receptor a4 subunit gene as a consequence of SEFL (Ponomarev et al., 2010) led us to speculate that during stress allopregnanolone at the a4containing receptors might act as a protective mechanism. However, allopregnanolone did 
not alter SEFL or fear memory for the trauma. Since we did not measure direct changes in $\mathrm{GABA}_{\mathrm{A}}$ receptor a4 subunit expression after acute administration of allopregnanolone under conditions of traumatic stress and because SEFL behavior was unaffected, we can only speculate that down-regulated expression of the $\mathrm{GABA}_{\mathrm{A}}$ receptors was not affected by allopregnanolone. Likewise, in the animals that received allopregnanolone on the day following the 15-shock trauma and before the single shock in the novel environment we saw no effect. In this case it is possible that because changes in receptor expression can occur very rapidly, that down-regulation of the $\mathrm{GABA}_{\mathrm{A}}$ receptor a4 subunit had already occurred as a consequence of trauma, and furthermore that by the time the allopregnanolone was administered there were fewer receptor targets, especially in the amygdala, at which to exert an effect. A final concern about the use of allopregnanolone is that allosteric modulators often act as feedback mechanisms in the brain. Thus, a surplus of allopregnanolone might have interfered with endogenous feedback mechanisms, producing contradictory effects to those of endogenous allopregnanolone release.

\section{Conclusion}

Many of the pharmacological treatments for anxiety disorders such as PTSD focus on ameliorating symptoms that are specifically related to the fear learning and memory of the trauma. These types of treatments, though they may be effective treatments for cognitive and declarative aspects of the disorder, do not affect symptoms like SEFL, which may be responsible for some of the treatment refractory symptoms of PTSD.

\section{Acknowledgements}

This work was supported by Supported by NIH grant RC1MH0088184 to MSF.

\section{References}

Adamec, R., Muir, C., Grimes, M., \& Pearcey, K. (2007). Involvement of noradrenergic and corticoid receptors in the consolidation of the lasting anxiogenic effects of predator stress. Behav Brain Res, 179(2), 192-207. doi: S0166-4328(07)00078-2 [pii] 10.1016/j.bbr.2007.02.001

American Psychiatric Association. (2000). Diagnostic criteria from DSM-IV-TR. Washington, D.C.: American Psychiatric Association.

Anagnostaras, S. G., Wood, S. C., Shuman, T., Cai, D. J., Leduc, A. D., Zurn, K. R., . . . Herrera, G. M. (2010). Automated assessment of pavlovian conditioned freezing and shock reactivity in mice using the video freeze system. Front Behav Neurosci, 4. doi: 158 [pii] 10.3389/fnbeh.2010.00158

Barbaccia, M. L., Concas, A., Serra, M., \& Biggio, G. (1998). Stress and neurosteroids in adult and aged rats. Exp Gerontol, 33(7-8), 697-712.

Bauer, K. P., Dom, P. M., Ramirez, A. M., \& O'Flaherty, J. E. (2004). Preoperative intravenous midazolam: benefits beyond anxiolysis. J Clin Anesth, 16(3), 177-183. doi: 10.1016/j.jclinane.2003.07.003S095281800400008X [pii]

Belelli, D., \& Lambert, J. J. (2005). Neurosteroids: endogenous regulators of the GABA(A) receptor. Nat Rev Neurosci, 6(7), 565-575. doi: nrn1703 [pii] 10.1038/nrn1703 
Berger, W., Mendlowicz, M. V., Marques-Portella, C., Kinrys, G., Fontenelle, L. F., Marmar, C. R., \& Figueira, I. (2009). Pharmacologic alternatives to antidepressants in posttraumatic stress disorder: a systematic review. Prog Neuropsychopharmacol Biol Psychiatry, 33(2), 169-180. doi: S0278-5846(08)00377-1 [pii] 10.1016/j.pnpbp.2008.12.004

Brantigan, C. O., Brantigan, T. A., \& Joseph, N. (1982). Effect of beta blockade and beta stimulation on stage fright. Am J Med, 72(1), 88-94. doi: 0002-9343(82)90592-7 [pii]

Brunello, N., Davidson, J. R., Deahl, M., Kessler, R. C., Mendlewicz, J., Racagni, G., . . . Zohar, J. (2001). Posttraumatic stress disorder: diagnosis and epidemiology, comorbidity and social consequences, biology and treatment. Neuropsychobiology, 43(3), 150-162. doi: nps43150 [pii]

Bustos, S. G., Giachero, M., Maldonado, H., \& Molina, V. A. (2010). Previous stress attenuates the susceptibility to Midazolam's disruptive effect on fear memory reconsolidation: influence of pre-reactivation D-cycloserine administration. Neuropsychopharmacology, 35(5), 1097-1108. doi: npp2009215 [pii] 10.1038/npp.2009.215

Cahill, L., Babinsky, R., Markowitsch, H. J., \& McGaugh, J. L. (1995). The amygdala and emotional memory. Nature, 377(6547), 295-296. doi: 10.1038/377295a0

Cahill, L., Pham, C. A., \& Setlow, B. (2000). Impaired memory consolidation in rats produced with beta-adrenergic blockade. Neurobiol Learn Mem, 74(3), 259-266. doi: 10.1006/nlme.1999.3950 S1074-7427(99)93950-3 [pii]

Cahill, L., Prins, B., Weber, M., \& McGaugh, J. L. (1994). Beta-adrenergic activation and memory for emotional events. Nature, 371(6499), 702-704. doi: 10.1038/371702a0

Charney, D. S. (2004). Psychobiological mechanisms of resilience and vulnerability: implications for successful adaptation to extreme stress. Am J Psychiatry, 161(2), 195-216.

Craske, M. G., Kircanski, K., Zelikowsky, M., Mystkowski, J., Chowdhury, N., \& Baker, A. (2008). Optimizing inhibitory learning during exposure therapy. Behav Res Ther, 46(1), 5-27. doi: S0005-7967(07)00205-7 [pii] 10.1016/j.brat.2007.10.003

Ehrlich, I., Humeau, Y., Grenier, F., Ciocchi, S., Herry, C., \& Luthi, A. (2009). Amygdala inhibitory circuits and the control of fear memory. Neuron, 62(6), 757-771. doi: S0896-6273(09)00426-7 [pii] 10.1016/j.neuron.2009.05.026

Fanselow, M. S. (1980). Conditioned and unconditional components of post-shock freezing. Pavlov J Biol Sci, 15(4), 177-182.

Fanselow, M. S., \& Kim, J. J. (1994). Acquisition of contextual Pavlovian fear conditioning is blocked by application of an NMDA receptor antagonist D,L-2-amino-5phosphonovaleric acid to the basolateral amygdala. Behav Neurosci, 108(1), 210-212.

Frank, M. J., O'Reilly, R. C., \& Curran, T. (2006). When memory fails, intuition reigns: midazolam enhances implicit inference in humans. Psychol Sci, 17(8), 700-707. doi: PSCI1769 [pii] 10.1111/j.1467-9280.2006.01769.x

Gerber, J. G., Freed, C. R., \& Nies, A. S. (1980). Antihypertensive pharmacology. West J Med, 132(5), 430-439.

Goisman, R. M., Allsworth, J., Rogers, M. P., Warshaw, M. G., Goldenberg, I., Vasile, R. G., . . . Keller, M. B. (1998). Simple phobia as a comorbid anxiety disorder. Depress Anxiety, 7(3), 105-112. doi: 10.1002/(SICI)1520-6394(1998)7:3<105::AIDDA2>3.0.CO;2-A [pii] 
Hamner, M. B., Robert, S., \& Frueh, B. C. (2004). Treatment-resistant posttraumatic stress disorder: strategies for intervention. CNS Spectr, 9(10), 740-752.

Jacobs, N. S., Cushman, J. D., \& Fanselow, M. S. (2010). The accurate measurement of fear memory in Pavlovian conditioning: Resolving the baseline issue. J Neurosci Methods, 190(2), 235-239. doi: S0165-0270(10)00234-7 [pii]

10.1016/j.jneumeth.2010.04.029

Janak, P. H., \& Gill, M. T. (2003). Comparison of the effects of allopregnanolone with direct GABAergic agonists on ethanol self-administration with and without concurrently available sucrose. Alcohol, 30(1), 1-7. doi: S0741832903000685 [pii]

Janak, P. H., Redfern, J. E., \& Samson, H. H. (1998). The reinforcing effects of ethanol are altered by the endogenous neurosteroid, allopregnanolone. Alcohol Clin Exp Res, 22(5), 1106-1112. doi: 00000374-199808000-00019 [pii]

Kessler, R. C., Sonnega, A., Bromet, E., Hughes, M., \& Nelson, C. B. (1995). Posttraumatic stress disorder in the National Comorbidity Survey. Arch Gen Psychiatry, 52(12), 1048-1060.

Kindt, M., Soeter, M., \& Vervliet, B. (2009). Beyond extinction: erasing human fear responses and preventing the return of fear. Nat Neurosci, 12(3), 256-258. doi: nn.2271 [pii] $10.1038 / \mathrm{nn} .2271$

Kobori, N., Hu, B., \& Dash, P. K. (2010). Altered adrenergic receptor signaling following traumatic brain injury contributes to working memory dysfunction. Neuroscience. doi: S0306-4522(10)01403-X [pii] 10.1016/j.neuroscience.2010.10.048

Liang, K. C., Juler, R. G., \& McGaugh, J. L. (1986). Modulating effects of posttraining epinephrine on memory: involvement of the amygdala noradrenergic system. Brain Res, 368(1), 125-133. doi: 0006-8993(86)91049-8 [pii]

McGhee, L. L., Maani, C. V., Garza, T. H., Desocio, P. A., Gaylord, K. M., \& Black, I. H. (2009). The effect of propranolol on posttraumatic stress disorder in burned service members. J Burn Care Res, 30(1), 92-97. doi: 10.1097/BCR.0b013e3181921f51

Muravieva, E. V., \& Alberini, C. M. (2010). Limited efficacy of propranolol on the reconsolidation of fear memories. Learn Mem, 17(6), 306-313. doi: 17/6/306 [pii] 10.1101/lm.1794710

Olatunji, B. O., Cisler, J. M., \& Deacon, B. J. (2010). Efficacy of cognitive behavioral therapy for anxiety disorders: a review of meta-analytic findings. Psychiatr Clin North Am, 33(3), 557-577. doi: S0193-953X(10)00044-4 [pii] 10.1016/j.psc.2010.04.002

Pibiri, F., Nelson, M., Guidotti, A., Costa, E., \& Pinna, G. (2008). Decreased corticolimbic allopregnanolone expression during social isolation enhances contextual fear: A model relevant for posttraumatic stress disorder. Proc Natl Acad Sci U S A, 105(14), 5567-5572. doi: 0801853105 [pii] 10.1073/pnas.0801853105

Pinna, G. (2010). In a mouse model relevant for post-traumatic stress disorder, selective brain steroidogenic stimulants (SBSS) improve behavioral deficits by normalizing allopregnanolone biosynthesis. Behav Pharmacol, 21(5-6), 438-450. doi: 10.1097/FBP.0b013e32833d8ba000008877-201009000-00008 [pii]

Ponomarev, I., Rau, V., Eger, E. I., Harris, R. A., \& Fanselow, M. S. (2010). Amygdala transcriptome and cellular mechanisms underlying stress-enhanced fear learning in a rat model of posttraumatic stress disorder. Neuropsychopharmacology, 35(6), 14021411. doi: npp201010 [pii] 10.1038/npp.2010.10 
Przybyslawski, J., Roullet, P., \& Sara, S. J. (1999). Attenuation of emotional and nonemotional memories after their reactivation: role of beta adrenergic receptors. $J$ Neurosci, 19(15), 6623-6628.

Purdy, R. H., Morrow, A. L., Moore, P. H., Jr., \& Paul, S. M. (1991). Stress-induced elevations of gamma-aminobutyric acid type A receptor-active steroids in the rat brain. Proc Natl Acad Sci U S A, 88(10), 4553-4557.

Rainnie, D. G., Bergeron, R., Sajdyk, T. J., Patil, M., Gehlert, D. R., \& Shekhar, A. (2004). Corticotrophin releasing factor-induced synaptic plasticity in the amygdala translates stress into emotional disorders. J Neurosci, 24(14), 3471-3479. doi: 10.1523/JNEUROSCI.5740-03.2004 24/14/3471 [pii]

Rasmusson, A., Pinna, G., Paliwal, P., Weisman, D., Gottschalk, C., Charney, D., Guidotti, A. (2006). Decreased Cerebrospinal Fluid Allopregnanolone Levels in Women with Posttraumatic Stress Disorder. Biological Psychiatry, 60(7), 704-713. doi: 10.1016/j.biopsych.2006.03.026

Rau, V., DeCola, J. P., \& Fanselow, M. S. (2005). Stress-induced enhancement of fear learning: an animal model of posttraumatic stress disorder. Neurosci Biobehav Rev, 29(8), 1207-1223. doi: S0149-7634(05)00060-6 [pii] 10.1016/j.neubiorev.2005.04.010

Rau, V., Oh, I., Laster, M., Eger, E. I., 2nd, \& Fanselow, M. S. (2009). Isoflurane suppresses stress-enhanced fear learning in a rodent model of post-traumatic stress disorder. Anesthesiology, 110(3), 487-495. doi: 10.1097/ALN.0b013e3181974f3e

Rauch, S. L., Shin, L. M., \& Phelps, E. A. (2006). Neurocircuitry models of posttraumatic stress disorder and extinction: human neuroimaging research--past, present, and future. Biol Psychiatry, 60(4), 376-382. doi: S0006-3223(06)00796-7 [pii] 10.1016/j.biopsych.2006.06.004

Rauch, S. L., Whalen, P. J., Shin, L. M., McInerney, S. C., Macklin, M. L., Lasko, N. B., Pitman, R. K. (2000). Exaggerated amygdala response to masked facial stimuli in posttraumatic stress disorder: a functional MRI study. Biol Psychiatry, 47(9), 769776. doi: S0006-3223(00)00828-3 [pii]

Roberts, N. P., Kitchiner, N. J., Kenardy, J., \& Bisson, J. I. (2010). Early psychological interventions to treat acute traumatic stress symptoms. Cochrane Database Syst Rev(3), CD007944. doi: 10.1002/14651858.CD007944.pub2

Rodriguez Manzanares, P. A., Isoardi, N. A., Carrer, H. F., \& Molina, V. A. (2005). Previous stress facilitates fear memory, attenuates GABAergic inhibition, and increases synaptic plasticity in the rat basolateral amygdala. J Neurosci, 25(38), 8725-8734. doi: 25/38/8725 [pii] 10.1523/JNEUROSCI.2260-05.2005

Roozendaal, B., Okuda, S., de Quervain, D. J., \& McGaugh, J. L. (2006). Glucocorticoids interact with emotion-induced noradrenergic activation in influencing different memory functions. Neuroscience, 138(3), 901-910. doi: S0306-4522(05)00840-7 [pii] 10.1016/j.neuroscience.2005.07.049

Rosen, J. B., \& Schulkin, J. (1998). From normal fear to pathological anxiety. Psychol Rev, 105(2), 325-350.

Shekhar, A., Truitt, W., Rainnie, D., \& Sajdyk, T. (2005). Role of stress, corticotrophin releasing factor (CRF) and amygdala plasticity in chronic anxiety. Stress, 8(4), 209219. doi: P3442332K575VH6G [pii] 10.1080/10253890500504557

Sher, L., \& Vilens, A. (2010). Neurobiology of post-traumatic stress disorder. Hauppauge, N.Y.: Nova Science Publishers. 
Smith, S. S., Shen, H., Gong, Q. H., \& Zhou, X. (2007). Neurosteroid regulation of GABA(A) receptors: Focus on the alpha4 and delta subunits. Pharmacol Ther, 116(1), 58-76. doi: S0163-7258(07)00070-8 [pii] 10.1016/j.pharmthera.2007.03.008

Southwick, S. M., Bremner, J. D., Rasmusson, A., Morgan, C. A., 3rd, Arnsten, A., \& Charney, D. S. (1999). Role of norepinephrine in the pathophysiology and treatment of posttraumatic stress disorder. Biol Psychiatry, 46(9), 1192-1204. doi: S0006-3223(99)00219-X [pii]

Stewart, S. H., Buffett-Jerrott, S. E., Finley, G. A., Wright, K. D., \& Valois Gomez, T. (2006). Effects of midazolam on explicit vs implicit memory in a pediatric surgery setting. Psychopharmacology, 188(4), 489-497. doi: 10.1007/s00213-006-0402-7

Thomas-Anterion, C., Koenig, O., Navez, M., \& Laurent, B. (1999). Midazolam effects on implicit and explicit memory processes in healthy subjects. Psychopharmacology (Berl), 145(2), 139-143.

Vaiva, G., Ducrocq, F., Jezequel, K., Averland, B., Lestavel, P., Brunet, A., \& Marmar, C. R. (2003). Immediate treatment with propranolol decreases posttraumatic stress disorder two months after trauma. Biol Psychiatry, 54(9), 947-949. doi: S0006322303004128 [pii]

van Stegeren, A. H., Everaerd, W., \& Gooren, L. J. (2002). The effect of beta-adrenergic blockade after encoding on memory of an emotional event. Psychopharmacology (Berl), 163(2), 202-212. doi: 10.1007/s00213-002-1163-6 


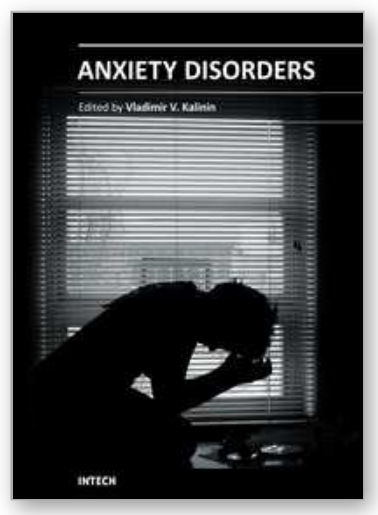

\author{
Anxiety Disorders \\ Edited by Prof. Vladimir Kalinin
}

ISBN 978-953-307-592-1

Hard cover, 324 pages

Publisher InTech

Published online 01, August, 2011

Published in print edition August, 2011

During the last 2-3 decades drastic research progress in anxiety issues has been achieved. It concerns mostly the study of different subtypes of anxiety and their treatment. Nevertheless, the data on anxiety pathogenesis is less elaborated, although here a multidimensional approach exists. It includes neurochemistry, pathophysiology, endocrinology and psychopharmacology. Again, we are able to recognize the multifarious sense of anxiety, and the present collective monograph composed of 16 separate chapters depicting the different aspects of anxiety. Moreover, a great part of book includes chapters on neurochemistry, physiology and pharmacology of anxiety. The novel data on psychopathology and clinical signs of anxiety and its relationship with other psychopathological phenomena is also presented. The current monograph may represent an interest and be of practical use not only for clinicians but for a broad range of specialists, including biochemists, physiologists, pharmacologists and specialists in veterinary.

\title{
How to reference
}

In order to correctly reference this scholarly work, feel free to copy and paste the following:

Virginia Long, Wendy Fujioka, Dorsa Amir and Michael Fanselow (2011). Pharmacological Resistance of Stress Enhanced Fear Learning in an Animal Model of Post-Traumatic Stress Disorder, Anxiety Disorders, Prof. Vladimir Kalinin (Ed.), ISBN: 978-953-307-592-1, InTech, Available from:

http://www.intechopen.com/books/anxiety-disorders/pharmacological-resistance-of-stress-enhanced-fearlearning-in-an-animal-model-of-post-traumatic-st1

\section{INTECH}

open science | open minds

\section{InTech Europe}

University Campus STeP Ri

Slavka Krautzeka 83/A

51000 Rijeka, Croatia

Phone: +385 (51) 770447

Fax: +385 (51) 686166

www.intechopen.com

\section{InTech China}

Unit 405, Office Block, Hotel Equatorial Shanghai

No.65, Yan An Road (West), Shanghai, 200040, China

中国上海市延安西路65号上海国际贵都大饭店办公楼 405 单元

Phone: +86-21-62489820

Fax: $+86-21-62489821$ 
(C) 2011 The Author(s). Licensee IntechOpen. This chapter is distributed under the terms of the Creative Commons Attribution-NonCommercialShareAlike-3.0 License, which permits use, distribution and reproduction for non-commercial purposes, provided the original is properly cited and derivative works building on this content are distributed under the same license. 